\title{
Optimisation of the Magnetic Circuit of a Measuring Head for Diagnostics of Steel-Polyurethane Load-Carrying Belts Using Numerical Methods
}

\author{
Hubert Ruta ${ }^{1}$, Tomasz Krakowski ${ }^{1}$ (D) and Paweł Lonkwic ${ }^{2, *}$ \\ 1 Department of Machinery Engineering and Transport, Faculty of Mechanical Engineering and Robotics, \\ AGH University of Science and Technology, 30-059 Kraków, Poland; hubert.ruta@agh.edu.pl (H.R.); \\ tomasz.krakowski@agh.edu.pl (T.K.) \\ 2 The State School of Higher Education, The Institute of Technical Sciences and Aviation, Pocztowa Street 54, \\ 22-100 Chełm, Poland \\ * Correspondence: plonkwic@pwszchelm.edu.pl; Tel.: +48-884-883-464
}

check for updates

Citation: Ruta, H.; Krakowski, T.; Lonkwic, P. Optimisation of the Magnetic Circuit of a Measuring Head for Diagnostics of Steel-Polyurethane Load-Carrying Belts Using Numerical Methods.

Sustainability 2022, 14, 2711.

https://doi.org/10.3390/su14052711

Academic Editor: Maxim

A. Dulebenets

Received: 30 December 2021

Accepted: 23 February 2022

Published: 25 February 2022

Publisher's Note: MDPI stays neutral with regard to jurisdictional claims in published maps and institutional affiliations.

Copyright: () 2022 by the authors Licensee MDPI, Basel, Switzerland. This article is an open access article distributed under the terms and conditions of the Creative Commons Attribution (CC BY) license (https:// creativecommons.org/licenses/by/ $4.0 /)$.

\begin{abstract}
The paper describes the process of a prototype head optimisation for magnetic diagnostics of steel-polyurethane load-carrying belts. The prototype, validated on a number of cranes, was subject to an improvement and optimisation attempt using numerical analysis of magnetic field distribution in the magnetic circuit, tested load-carrying belt, and environment. The analysis was carried out in the ANSYS environment using PDS—Probabilistic Design System tools (DOE-Design of Experiment). Taking the dimensions of individual elements of the magnetic circuit, material densities, and magnetic material properties as the input data, the magnetic circuit was optimised with respect to metrological properties as well as mass and size criteria. Based on the analyses carried out and the results obtained, the head design was modernised, which involved changing the geometry of elements forming the magnetic circuit. Based on observations made during tests of the prototype version of the device performed on real objects, several improvements were also proposed, consisting of the replacement of selected components with elements printed in the FDM technology. The correctness of the performed numerical analyses was verified by comparing the measured and calculated values of the total magnetic field induction in the defined plane of the magnetic circuit. The prototype versions of heads before and after modernisation were subject to comparative tests. Under laboratory conditions, both versions of heads were used to diagnose the steel-polyurethane load-carrying belts with modelled damages. The obtained test results and their statistical characteristics were analysed in detail.
\end{abstract}

Keywords: passenger lifts; diagnostics; non-destructive testing; ropes; magnetic field; finite element method (FEM)

\section{Introduction}

The development of machinery and equipment is associated not only with the change of standards and energy consumption, but also with management methods and life cycle assessment. Development-related changes are widely described in the articles of many authors and concern many aspects of engineering. Nevertheless, there are areas whose secrets are not expansively presented in international journals. Such an example would undoubtedly be the field related to material handling and, more specifically, lifting equipment. One of the basic directions of development of lifting equipment is related to the drive system in terms of reducing its size and energy requirements, as well as the use of load-carrying belt transmissions and new designs of load-carrying belts.

A detailed analysis of the state of the art in the subject of this paper showed that this topic has not been widely covered. The publications presented below do not address the topic directly, but only bear some resemblance to the research presented in this paper. 
So far, load-carrying belt system solutions have been based on the cooperation of a steel wire rope with a friction wheel, creating a kinematic pair. According to the standard [1], there is a condition that applies to this pair: the diameter of the friction wheel must be at least 40 diameters of the rope. When this condition is met, the used reducers have large dimensions and it is not possible to use them in all lifting devices. In modern hoisting installations, the gearless drives with small diameter wheels or shafts are used, which very often form a kinematic pair with plastic-coated belts. In such cases, the condition described above no longer applies because the standard [1] refers only to steel wire ropes and does not cover plastic-coated load-carrying belts.

Depending on the manufacturer and the required strength properties, the loadcarrying belts vary in geometric dimensions, cord diameter, and the type of material used as their carcass. Figure 1 shows the dimensions and cross-section of an example of a steel-polyurethane (SP) load-carrying belt. The great advantage of this type of loadcarrying belt is that, with similar strength properties as traditional wire ropes, it allows the use of small diameter drive wheels, and the use of carcass eliminates the need of their maintenance and increases friction between the load-carrying belt and the drive shaft. The flat shape increases the contact area, which also has a positive effect on stress distribution. The application of SP belts is not limited to the drives for passenger cranes but this solution is also used in other lifting devices as well as in drives for fans, water pumps, compressors, in power steering systems for automatically opening doors, injection pumps, or camshafts [2-4].

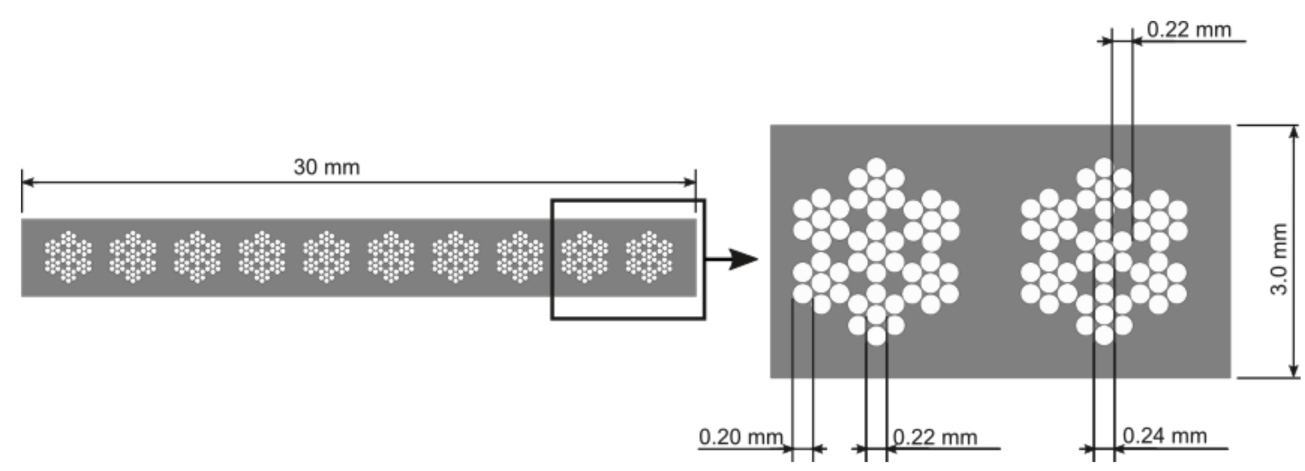

Figure 1. Cross-section of a steel-polyurethane load-carrying belt (SP) (own source).

The search for energy savings in the operation of lifting equipment is a response to market needs. Activities related to the reduction of energy demand through the introduction of new design solutions must be carried out in a sustainable manner while maintaining an acceptable level of safety. SP belts, just as traditional wire ropes, are the structures with limited durability and their wear process is irreversible. Safe operation is possible until a certain level of wear (conventional limit value) is reached, beyond which the load-carrying belt becomes unfit for further use and must be replaced. The state of unfitness is reached as a result of the accumulation of various types of damages which, according to the accepted criteria (so-called dump criteria), exceed the limit value. The load-carrying belt dump criteria can be based on:

- loss of metallic cross-section,

- permissible amount of steel wire scrap,

- change in load-carrying belt dimensions,

- degree of deformation,

- $\quad$ wear of integral load-carrying belt material.

Due to the construction of SP belts, it is very difficult to assess their technical condition. The visual inspection of load-carrying belt is impractical and it is hard, and sometimes even impossible, to detect many failures using this method. Therefore, the technical condition assessment of steel wire ropes embedded in plastic carcass becomes an essential issue regarding their safe operation. This makes it necessary to introduce new diagnostic 
methods, e.g., magnetic flaw detection, the use of which has been described in a number of publications [4-7].

In one publication [4], the authors described the problem of technical diagnostics of steel-polyurethane load-carrying belts. They presented one of the first diagnostic systems consisting of a head for magnetic testing, a recorder and software. They discussed the expert advisory system which is a part of the software developed for the analysis of the results obtained. The authors also mentioned the need to develop acceptance criteria and correlation of magnetic test results with load-carrying belt fatigue tests.

Another publication [5] presents the results of work related to the design of a magnetic circuit for diagnostic heads used in magnetic testing of wire ropes. The authors presented the results of a number of analyses carried out in the Computer Aided Engineering (CAE) ANSYS Workbench software aimed at multi-criteria optimisation of the magnetic circuit in terms of its mass and metrological properties.

In [6], the authors discussed the available solutions of measuring heads for magnetic testing of steel wire ropes in plastic carcass and flat SP belts. They presented the results of measurement which were carried out on a real object within 3 years. They confirmed the applicability of equipment described in the article, and the tests performed on the same load-carrying belts carried out in subsequent years prove the repeatability of the detected damage location and the possibility of quantitative evaluation of its growth.

In [7], the authors described the possibility of using the magnetic method to diagnose the guides of lifting devices where, similarly to load-carrying belts, there was a change in the magnetic field dispersion flux in the area of discontinuity of the guide working surface.

In $[8,9]$, the authors dealt with the subject of diagnostic tests of steel wire ropes using the magnetic method. One article [8] compared the functional features of mine hoist ropes determined on the basis of visual, magnetic, and strength tests. The other [9] presented the possibility of applying wavelet analysis in the evaluation of signals recorded during magnetic testing. The theoretical basis and the principle of selecting the wavelet type required in the analysis were described. The results of tests carried out on a belt with modelled faults were also presented.

Furthermore, the issues related to the simulation of magnetic field were described in [10-17]. The authors also extensively described the issues related to diagnostics and non-destructive methods in various problems of mechanical engineering [18-26].

\section{Testing Methodology}

The magnetic wire rope testing method is a non-destructive one. It consists of detecting defects in the metallic cross-section of ropes which were previously magnetised longitudinally with a permanent magnetic field. If there is a defect, a disturbance of the magnetic field forces appears around the ferromagnet magnetised in a permanent magnetic field. This disturbance also occurs in the space surrounding the tested rope (6) and can be interpreted and analysed as an external magnetic stray field (1), as shown in Figure 2. The disturbance size is usually related to the size and position of the defect. The basic set of measuring equipment consists of two units: a measuring head unit and a recorder unit or other device that processes the measurement results. The main components of the magnetic head are the magnetic circuit of the measuring head, which is defined as a closed flux path of magnetic induction, being a part of the magnetic field with higher energy density, as compared to the surrounding parts, and the sensors (2) which are placed in the symmetry plane of the head. The magnetic circuit of the magnetic head, the diagram of which is shown in Figure 2, comprises permanent magnets which are the source of magnetic field (3), a magnetic jumper (4), and poles (5). The information about rope faults (6) is contained in the transversal By component of the magnetic stray flux (1) in the discontinuity occurrence area (7) (Figure 2) [27-29]. 


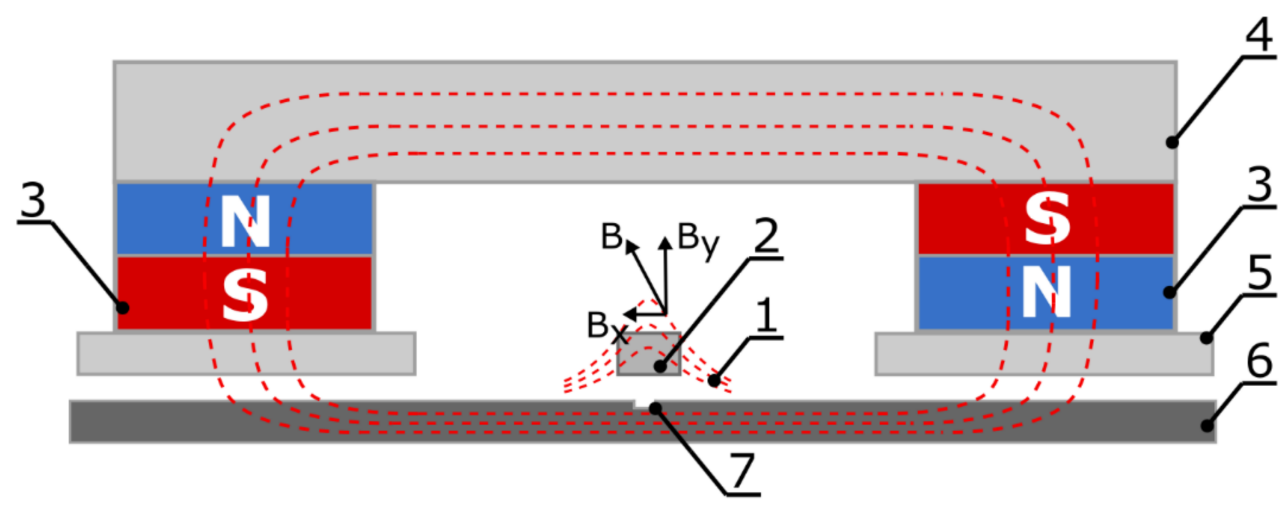

Figure 2. The essence of magnetisation and defect detection using the magnetic method (1-magnetic stray field, 2-sensor, 3-permanent magnet, 4-magnetic jumper, 5-pole piece, 6-tested rope, 7 -defect) (own source based on $[27,28]$ ).

In the case of SP belts, the magnetic method is used to locate discontinuities in the form of wire breaks. That is why only the sensors of step cross-sectional change (inductive ones) are used in the heads being constructed. A change of the transversal component By (Figure 2) of magnetic stray flux (1) over the tested element is detected by the sensor (2) and recorded in the form of a change of the electromotive force of induction. According to Faraday's law, the value of electromotive force is described by Formula $1[28,30]$.

$$
S E M=\varepsilon=-N \frac{d \varnothing_{B y}}{d t}
$$

where:

$\varepsilon$-electromotive force of induction,

$N$ - the number of turns of wire in the tightly wound coil

$\emptyset_{B y}$ - magnetic induction flux of the stray field (transversal component),

t-time.

The principle of sensor operation and the necessity to test the whole rope length forces the rope to move in relation to the head. In the case of load-carrying belt testing in passenger elevators, the head is mounted stationary and the ropes move inside the measuring system at the revision speed of the crane.

\section{Magnetic Circuit Optimisation Using Numerical Analyses}

The construction of the head for magnetic testing is determined mainly by the magnetic circuit. The dimensions of individual elements of the magnetic circuit determine the dimensions of the entire head and its mass, taking into account the space for sensing elements (inductive sensor). The overriding parameters are the metrological properties of the measuring device. It is mainly the dimensions of permanent magnets and the properties of the magnetically hard material and the associated B-H (Figure 3a) demagnetisation curve that determine the level of magnetic energy in the magnetic circuit. Moreover, the steel material (B-H magnetisation curve) (Figure 3b) from which the other elements of the magnetic circuit are made, i.e., the jumper or the pole pieces, are important. The dimensions of these elements and their mutual geometric relationships influence the method and uniformity of magnetic flux distribution to all steel wire ropes in the cross-section of the tested load-carrying belt. Adopting the dimensions of individual elements of the magnetic circuit, the material densities, and the magnetic material properties as the input, we can talk about the structure optimisation in terms of the criteria, such as dimensions, mass, and metrological properties. Minimisation of the first two criteria is important due to the ergonomics of using the device when working at heights in limited assembly spaces, and additionally, it has an impact on the time of installation and disassembly (minimisation of the time when an object is out of operation when performing diagnostic tests of, for example, 
a crane). The third criterion is directly related to the degree of steel wire rope magnetisation and the intensity of the stray field generated by possible defects (cracks). Many years of experience in designing and constructing the heads for magnetic testing of ferromagnetic structures prove that the best detectability of defects is obtained when the tested material is magnetised to the level of $B \geq 1.4 \mathrm{~T}$ induction. The effect of stray field intensification is the better the more the material magnetisation level is close to the saturation induction on the $\mathrm{B}-\mathrm{H}$ curve. This has a direct effect on the diagnostic signal quality, enables maximisation of the signal-to-noise ratio, and increases the detectability of even a very small defect (e.g., 3 broken wires equal to $0.094 \mathrm{~mm}^{2}$ loss of metallic cross-section in relation to the metallic cross-section of the entire belt that is $16.32 \mathrm{~mm}^{2}$ ) [31-34].
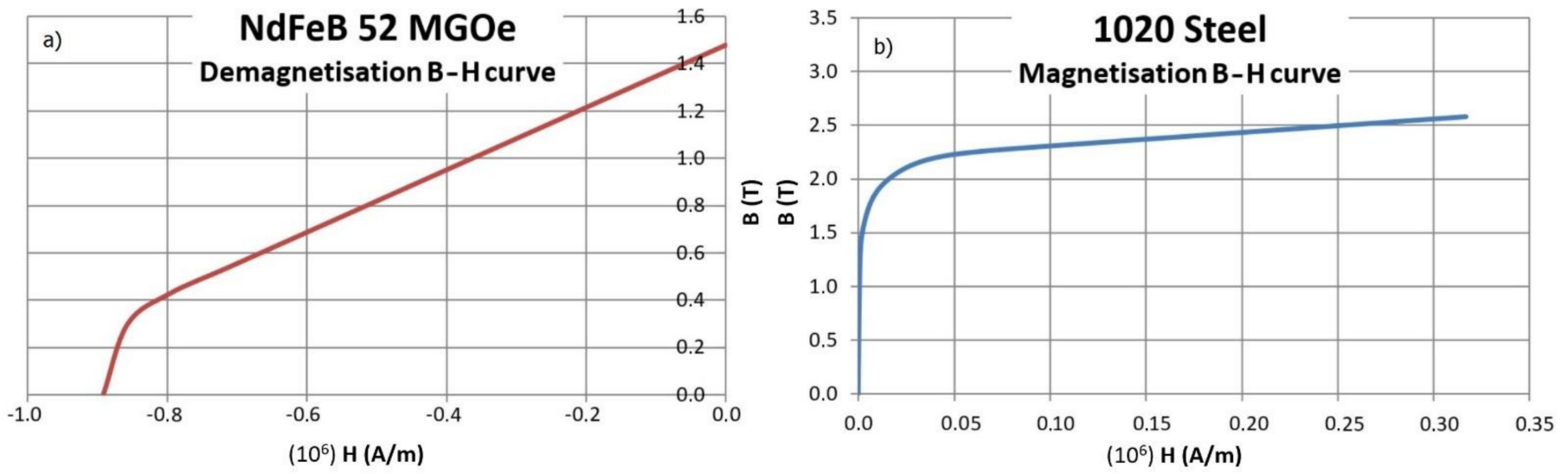

Figure 3. (a) Demagnetisation curve B-H of hard magnetic material NdFeB 52 MGOe (magnets); (b) magnetisation curve B-H of steel 1020 (elements, i.e., jumper, pole pieces, etc.) (own source based on [35]).

The prototype head, despite its successful operation validated on many objects, was subject to an effective attempt of improvement and optimisation using numerical analyses concerning the distribution of magnetic field in the magnetic circuit, tested load-carrying belt, and environment. The analyses were carried out in the ANSYS environment using PDS—Probabilistic Design System (DOE-Design of Experiment) tools. For the purpose of the analyses, a geometric (Figure 4a) and numerical (discretized) model (Figure $4 \mathrm{~b}$ ) of the magnetic circuit was developed, containing [31]:

- 2 oppositely polarised permanent magnets of $\mathrm{NdFeB}$ (neodymium-iron- boron) type,

- 2 pole pieces distributing the magnetic flux to a load-carrying belt,

- a magnetic jumper to close the magnetic circuit from below, and

- 12 steel wire ropes forming a load-carrying cable (belt).

The adopted optimisation input parameters (decision variables) were the technical parameters related to the dimensions of the magnetic circuit elements, i.e., the jumper, magnets, pole pieces, but also the steel wire ropes in the load-carrying belt and the air gap between the pole pieces and the belt. For the design elements of the circuit included in the head, the length of the element was assumed to be marked as $X$, width as $Y$, and height as $Z$, with appropriate indices, where index $\mathrm{z}$ denotes a jumper, $\mathrm{n}$ a pole piece, and $\mathrm{m}$ a magnet, according to Table 1 . All the input parameters along with their own designations and symbols (P1-P12) given by the system using PDS, as well as the defined variation range, are presented in Table 1 . The primary values of each parameter in the prototype version of the head were also indicated, which at the same time constitute the initial (starting) values for numerical analyses. The range of variability was adopted based on the analysis of functional possibilities, previous experience in the shaping of magnetic circuits, and certain limitations related to, e.g., XYZ dimensions of the sensing system necessary to be built inside the head, dimensions of the connection socket and its anticipated location, width of the load-carrying belt, etc. [31]. 

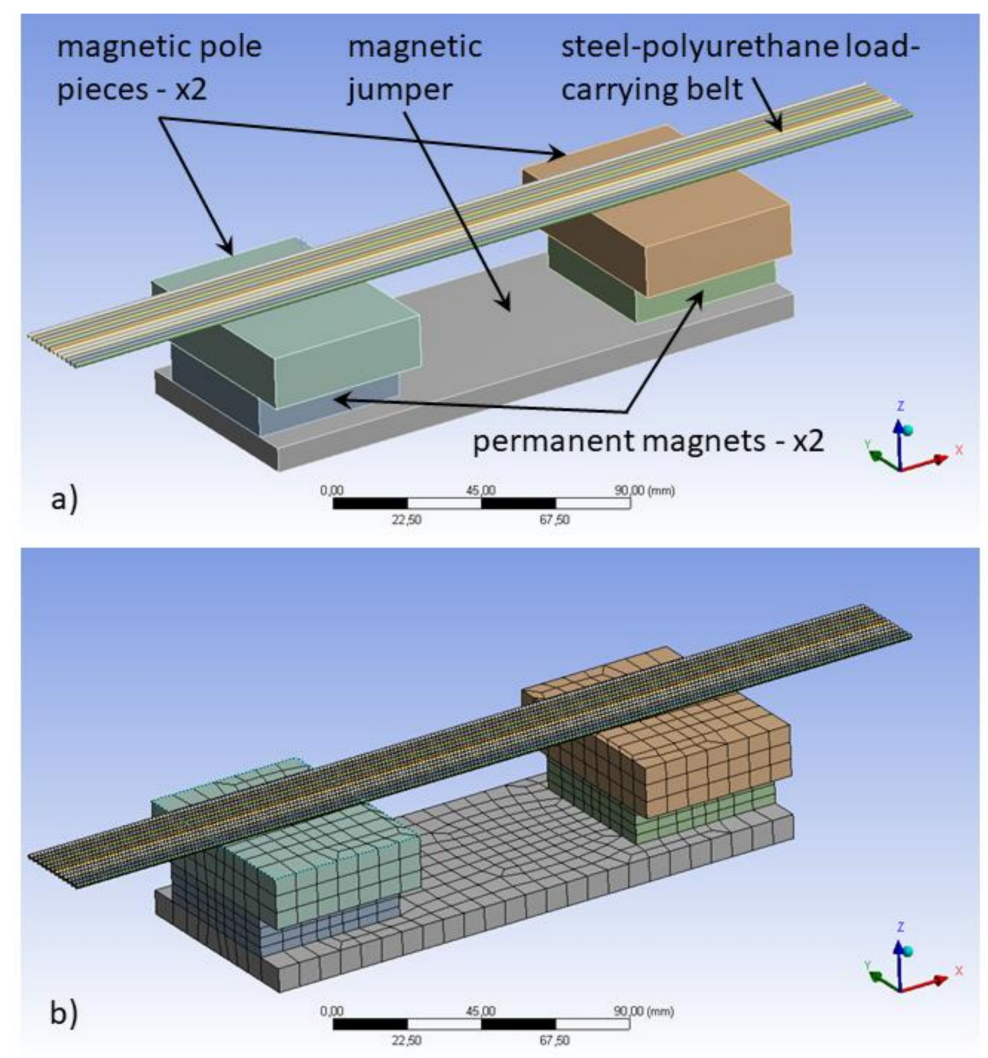

Figure 4. Geometrical (a) and numerical (b) (discrete) model of the magnetic head with the loadcarrying belt under tests (own source).

Table 1. Optimisation input parameters.

\begin{tabular}{|c|c|c|c|c|c|c|c|}
\hline \multirow{2}{*}{ Parameter Name } & \multirow{2}{*}{ Unit } & \multirow{2}{*}{$\begin{array}{l}\text { Parameter } \\
\text { symbol }\end{array}$} & \multirow{2}{*}{$\begin{array}{l}\text { ANSYS } \\
\text { Symbol }\end{array}$} & \multirow{2}{*}{ Initial Value } & \multicolumn{2}{|c|}{ Range of Variability } & \multirow{2}{*}{ Target Value } \\
\hline & & & & & Minimum & Maximum & \\
\hline $\begin{array}{l}\text { Length of the } \\
\text { magnetic jumper }\end{array}$ & $(\mathrm{mm})$ & $x_{z}$ & P1 & 195 & 150 & 250 & $?$ \\
\hline $\begin{array}{l}\text { Width of the } \\
\text { magnetic jumper }\end{array}$ & $(\mathrm{mm})$ & $\mathrm{Y}_{\mathrm{z}}$ & P2 & 70 & 30 & 100 & $?$ \\
\hline $\begin{array}{l}\text { High of the } \\
\text { magnetic jumper }\end{array}$ & $(\mathrm{mm})$ & $\mathrm{Z}_{\mathrm{z}}$ & P3 & 10 & 3 & 15 & $?$ \\
\hline $\begin{array}{l}\text { Length and width } \\
\text { of the magnet }\end{array}$ & $(\mathrm{mm})$ & $\mathrm{X}_{\mathrm{m}}$ & P5 & 50 & 20 & 75 & $?$ \\
\hline High of the magnet & $(\mathrm{mm})$ & $\mathrm{Z}_{\mathrm{m}}$ & P6 & 13 & 5 & 35 & $?$ \\
\hline Pole piece length & $(\mathrm{mm})$ & $X_{n}$ & P7 & 52 & 30 & 70 & $?$ \\
\hline Pole piece width & $(\mathrm{mm})$ & $Y_{n}$ & P8 & 70 & 30 & 100 & $?$ \\
\hline Pole piece height & $(\mathrm{mm})$ & $Z_{n}$ & P9 & 17 & 5 & 25 & $?$ \\
\hline Steel rope diameter & $(\mathrm{mm})$ & d & P11 & 1.6 & 1 & 2 & $?$ \\
\hline Air gap & $(\mathrm{mm})$ & $\mathrm{Z}_{\mathrm{sz}}$ & P12 & 4.7 & 2 & 8 & $?$ \\
\hline
\end{tabular}

Similarly, Table 2 presents the defined simulation output parameters and the designations imposed on them by the PDS system (P15-P32) used in the following part of the study. The output parameters were the masses of individual elements, the magnetic induction inside them (in their centres), and, most important from the metrological point of view, the magnetic induction in steel wire ropes. The last parameter was verified for the central as well as outer wire ropes (on the left and right side in the cross-section of the load-carrying belt) [31]. 
Table 2. Optimisation output parameters.

\begin{tabular}{cccc}
\hline Parameter Name & Unit & Parameter symbol & ANSYS Symbol \\
\hline Mass of the magnetic jumper & $(\mathrm{kg})$ & $\mathrm{M}_{\mathrm{z}}$ & $\mathrm{P} 15$ \\
\hline Mass of the magnet & $(\mathrm{kg})$ & $\mathrm{M}_{\mathrm{m}}$ & $\mathrm{P} 16$ \\
\hline Mass of the pole piece & $(\mathrm{kg})$ & $\mathrm{M}_{\mathrm{n}}$ & $\mathrm{P} 17$ \\
\hline $\begin{array}{c}\text { Magnetic induction-right wire rope } \\
\text { Magnetic induction-left wire rope }\end{array}$ & $(\mathrm{mT})$ & $\mathrm{B}_{\mathrm{lp}}$ & $\mathrm{P} 18$ \\
\hline $\begin{array}{c}\text { Magnetic induction-centre } \\
\text { wire rope }\end{array}$ & $(\mathrm{mT})$ & $\mathrm{B}_{\mathrm{ll}}$ & $\mathrm{P} 19$ \\
\hline $\begin{array}{c}\text { Magnetic induction in the centre of } \\
\text { the magnetic jumper }\end{array}$ & $(\mathrm{mT})$ & $\mathrm{B}_{\mathrm{ls}}$ & $\mathrm{P} 20$ \\
\hline $\begin{array}{c}\text { Magnetic induction at the centre of } \\
\text { the magnet }\end{array}$ & $(\mathrm{mT})$ & $\mathrm{B}_{\mathrm{zw}}$ & $\mathrm{P} 24$ \\
\hline $\begin{array}{c}\text { Magnetic induction in the centre of } \\
\text { the pole piece }\end{array}$ & $(\mathrm{mT})$ & $\mathrm{B}_{\mathrm{mag}}$ & $\mathrm{P} 28$ \\
\hline
\end{tabular}

Based on the assumed variability ranges of decision-making input parameters, more than 149 different combinations of these parameters with determined values were generated in the PDS tool. For each of these sets of parameters, the numerical calculations of magnetic field distributions in the magnetic circuit and in its surroundings were carried out by properly configuring the ANSYS system.

The electromagnetic field distribution in any 3D space is determined by four Maxwell equations. They can take a differential (as below) or integral form. At the same time, these are basic equations for calculation systems that make use of FEM or BEM, including, among others for the ANSYS system used in this research, where Equations (2) and (4) refer to the magnetic field description, while Equations (3) and (5) refer to electric field [7,31,36,37].

$$
\begin{gathered}
\nabla \times \vec{H}=\operatorname{rot} \vec{H}=\vec{J}+\frac{\partial \vec{D}}{\partial t} \\
\nabla \times \vec{E}=\operatorname{rot} \vec{E}=-\frac{\partial B}{\partial t} \\
\nabla \cdot \vec{B}=\operatorname{div} \vec{B}=0 \\
\nabla \cdot \vec{D}=\operatorname{div} \vec{D}=\rho
\end{gathered}
$$

where:

$$
\begin{aligned}
& \vec{H}=\text { vector value } \\
& {[]=\text { matrix }} \\
& \nabla=\text { nabla (gradient operator) } \nabla=\left[\begin{array}{lll}
\frac{\partial}{\partial x} & \frac{\partial}{\partial y} & \frac{\partial}{\partial z}
\end{array}\right]=\vec{i} \frac{\partial}{\partial x}+\vec{j} \frac{\partial}{\partial y}+\vec{k} \frac{\partial}{\partial z} \vec{i}, \vec{j}, \vec{k}-
\end{aligned}
$$
axis unit vectors (versors)

$\nabla \times=$ rot $=$ rotation operator (rotation is defined as a vector product of a nabla vector and another vector, the result of which is a vector)

$\nabla \cdot=$ div $=$ divergence operator (divergence is defined as a scalar product of a nabla vector and another vector, the result of which is a scalar)

$$
\begin{aligned}
& \vec{H}=\text { magnetic field intensity vector }\left(\frac{A}{m}\right) \\
& \vec{J}=\text { electric current density vector }\left(\frac{A}{m^{2}}\right) \\
& \vec{D}=\text { electric field induction vector }\left(\frac{C}{m^{2}}\right) \text { (Maxwell called it a movement vector but to avoid }
\end{aligned}
$$
misunderstanding and coincidence with mechanical movement, here we use the electric flux density or electric induction term.)

$$
t=\operatorname{time}(s)
$$




$$
\begin{aligned}
& \vec{E}=\text { electric field intensity vector }\left(\frac{V}{m}\right) \\
& \vec{B}=\text { magnetic field induction vector }(T) \text { or }\left(\frac{W b}{m^{2}}\right) \\
& \rho=\text { total density of electric load }\left(\frac{C}{m^{3}}\right)
\end{aligned}
$$

The full form of differential equations, based on which the issues related to magnetic field distribution in the ANSYS system are solved numerically, was presented by the authors in the publication [7] where they described the issues of using the magnetic stray field in diagnostics and evaluation of passenger lift guidance systems for their technical condition.

The main purpose of PDS (Probabilistic Design System) tools is to obtain answers about the process and correlation of its input and output parameters, by replacing the proven conservative deterministic methods with the probabilistic design techniques. The concept (PDS) assumes a random distribution for all defined critical input variables, as well as the determination of sensitivity of their effect on key output parameters. The key simulation outputs are defined as the unknown random output parameters. During the probabilistic analysis, the multiple analysis loops (iterations) are made to calculate the random output parameters as the function of a set of random input variables [38-41].

The result of the conducted numerical calculations related to the mentioned head for the SP load-carrying belt was to obtain 149 sets of discrete output parameter values (mass, magnetic induction) being the response to predefined input parameters (dimensions). As a consequence, it was possible to find a correlation between the design parameters of the head and mainly its metrological properties by analysing different design scenarios.

Based on these determined sets of parameters and their correlations, the approximated graphical nomograms and the response planes (so-called "Response Surfaces") were developed (Figure 5). In contrast to the discrete sets of correlations, they allow an approximate search for correlations in a continuous manner in the analysed range of input parameter variation and in the corresponding output parameters, also in a continuous manner [38-41].

It should be noted that "Response Surfaces" (Figure 5) enable to read the data in a continuous manner within their limits, but they are not the ideal result tools because using them is fully functional and convenient only when we have their digital version and the reading is carried out by computer, by placing a cursor in the given point of the graph (surface) - the reading of 2 values of input variables and the corresponding 1 output variable. Using them in an analogue form (e.g., after printing), especially in isometric projection (Figure 5), is not very practical. However, this does not diminish their effectiveness as a predictive element. For this reason, mainly more practical 2D charts and nomograms have been presented, i.e., "slice" charts, which have an output quantity on the vertical axis and one of the interdependent input quantities on the horizontal axis. The second input quantity is represented by coloured curves with a legend. Therefore, the above features of the nomogram take precedence over the response plots when used in an analogue way [38-41].

Thus, Figure 5 presents the 3D "Response Surface" concerning changes in the output parameter P20 (induction in the central wire rope) as a function of a change in the input parameters P11 (wire rope diameter) and P12 (air gap). Due to the impractical nature of the result presentation, it was replaced by an equivalent-slice type nomogram in Figure 6 . The induction in the central wire rope of the load-carrying belt (P20) is presented on the vertical axis as a function of the air gap between the pole pieces and the load-carrying belt (on the horizontal axis) (P12). Each of the curves forming the nomogram, marked with an appropriate colour, corresponds to a step change of the parameter P11 (steel wire rope diameter), each time by a step of $0.0417 \mathrm{~mm}$. 


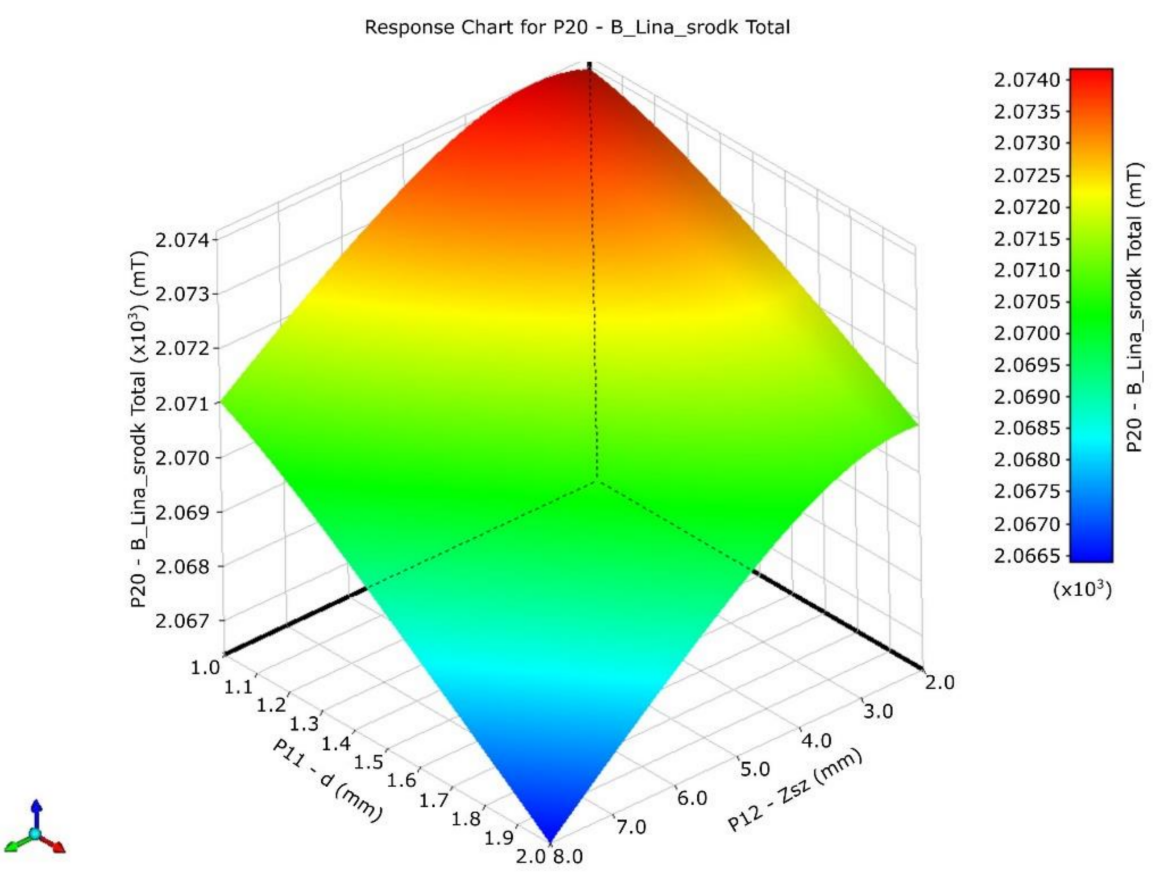

Figure 5. 3D response surface of the output parameter P20 (induction in the central wire) as a function of changing the input parameters P11 (wire rope diameter) and P12 (air gap) (own source).

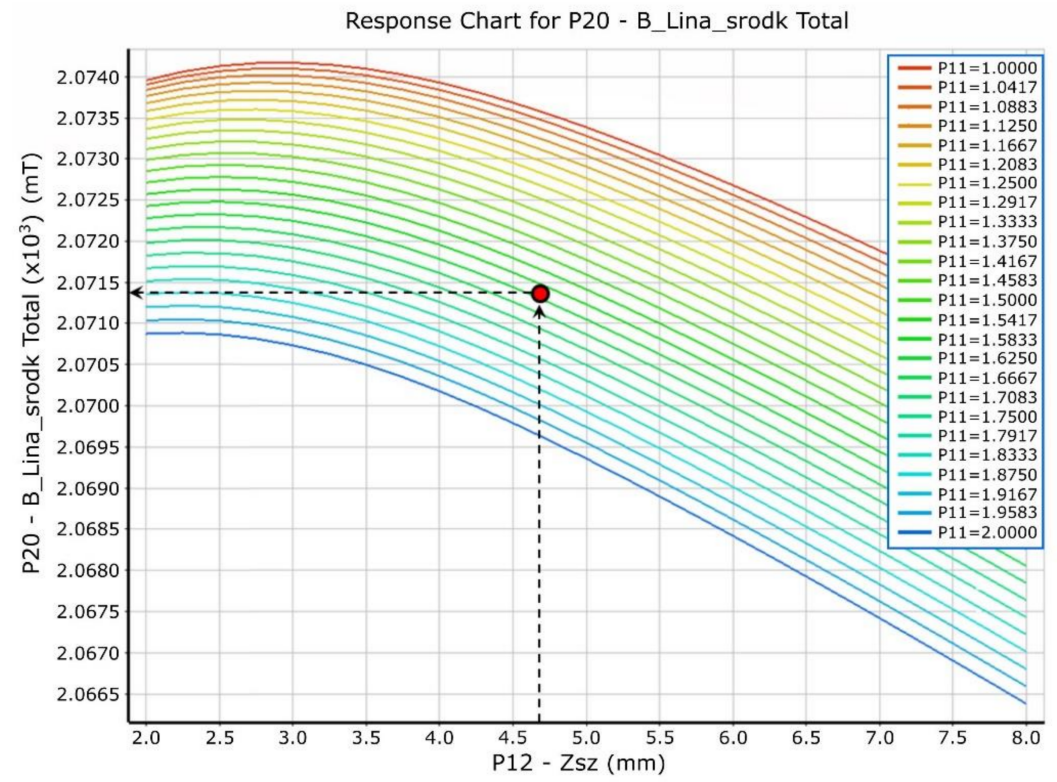

Figure 6. Nomogram (slice plot)—response of output parameter P20 (induction in central wire rope) as a function of change in input parameters P11 (wire rope diameter) and P12 (air gap) (own source).

When analysing the nomogram in Figure 6 concerning the influence of the parameters P11 (d-wire diameter) and P12 ( $Z_{\mathrm{sz}}$ - air gap) on the possible value of the induction in the wire rope of the load-carrying belt P20 (Bl), it should be noted that as the wire diameter increases, the induction to which it can be magnetised decreases. Bearing in mind that the load-carrying belt consists of several wire ropes, the total increase in metallic cross-sectional area resulting from an increase of a single rope diameter, with a constant value of the magnetic flux in the circuit, generates increasingly smaller values of induction in the steel wire rope. The situation is similar when the value of the gap between the magnetised wire ropes and the pole piece increases. As this gap increases, the magnetic flux has a hindered flow path. The total value of magnetic flux leakage around the magnetic circuit 
also increases (flux losses which are neglected in simplified calculations due to the assumed principle of flux continuity in an unbranched circuit). The gaps in the magnetic circuit also directly influence the location of the magnet operating point in the demagnetisation curve $\mathrm{BH}$, which is also confirmed by the nomogram in Figure 6. Figures 7 and 8 present the dependence of magnetic induction of the central wire rope of a load-carrying belt as a function of the head magnet dimensions. The induction is treated as a metrological parameter that has an influence on detectability of defects.

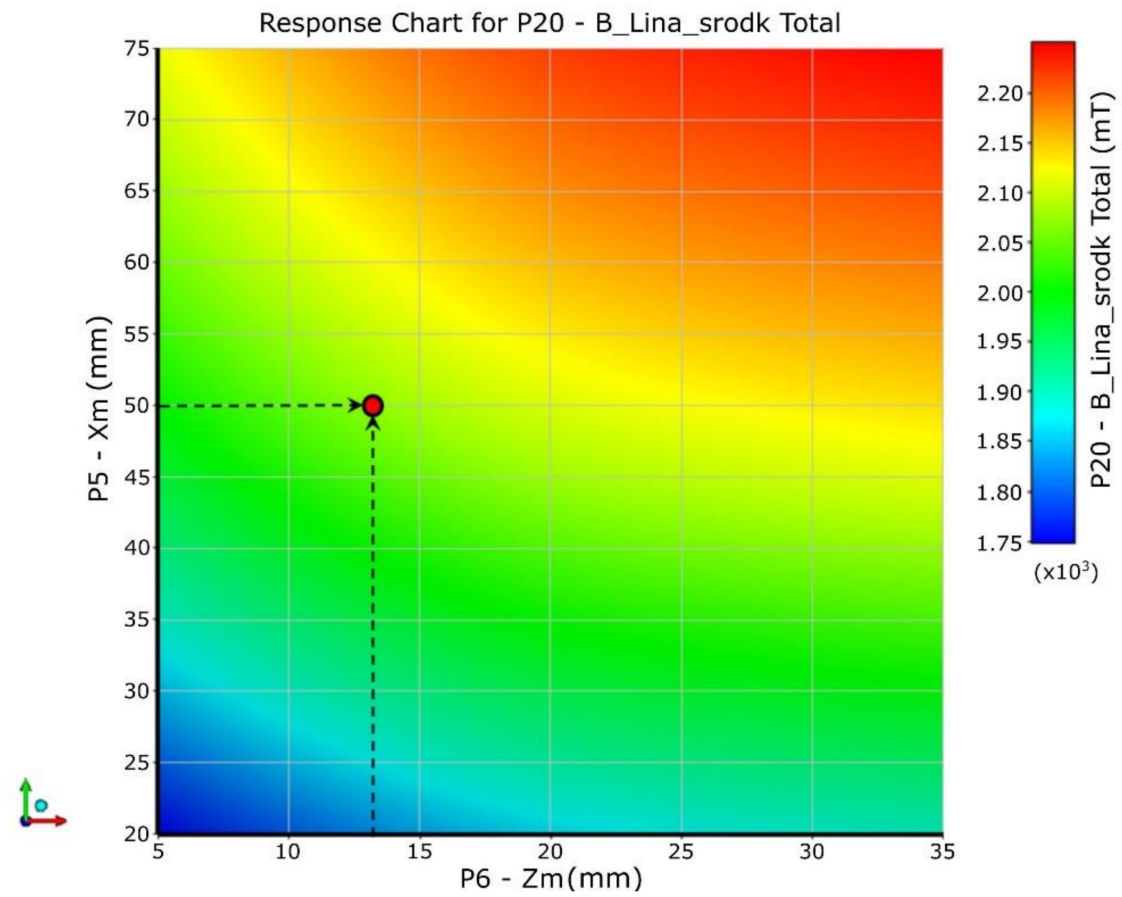

Figure 7. 2D response surface of the output parameter P20 (induction in central wire rope) as a function of input parameters P5 (magnet width) and P6 (magnet height) (own source).

The mentioned actions enabled a conscious and more precise selection of input parameters (dimensions) to achieve a specific goal. The overriding metrological objective was to obtain higher values of magnetic field induction in the wire ropes of the tested loadcarrying belt, reaching up to the wire rope material magnetic saturation level of about $2.1 \mathrm{~T}$. This was achieved by appropriate selection of parameters of magnets, air gap, and other circuit elements in relation to the wire rope diameter. Secondly, attention was also paid to the criteria related to the minimisation of the device weight and dimensions. Analysing the described nomograms and response surfaces in a digitised form, the specific dimension values of individual structural elements of magnetic circuit were selected and a modified version of the head was built.

In order to confirm the correctness of numerical analyses performed, a simple comparative verification with the results of real measurements of magnetic field induction was carried out in selected areas in the vicinity of the magnetic circuit. For the variant of the head after modernisation, the magnetic field induction was measured in a plane parallel to the upper surface of head pole pieces at a distance of $3 \mathrm{~mm}$ from them. The measurement was performed with a resolution of about $5 \mathrm{~mm}$ in both directions of the XY plane in an area having the $X 220 \mathrm{~mm}$ and $Y 120 \mathrm{~mm}$ dimensions, which gave the total of 1125 measurement points (Figure 9) [31].

For the variant of the head before modernisation, no similar comparative analysis was carried out as it was constructed based on previous in-house experience in designing magnetic circuits for the devices used in magnetic flaw detection. Due to the fact that the originally achieved results showed real metrological usefulness of the device on objects, there was no need to numerically check the original variant. However, being aware of 
the influence of technical parameters of the magnetic circuit on metrological properties of the device, the scientific optimisation efforts using FEM were undertaken, as described in the paper.

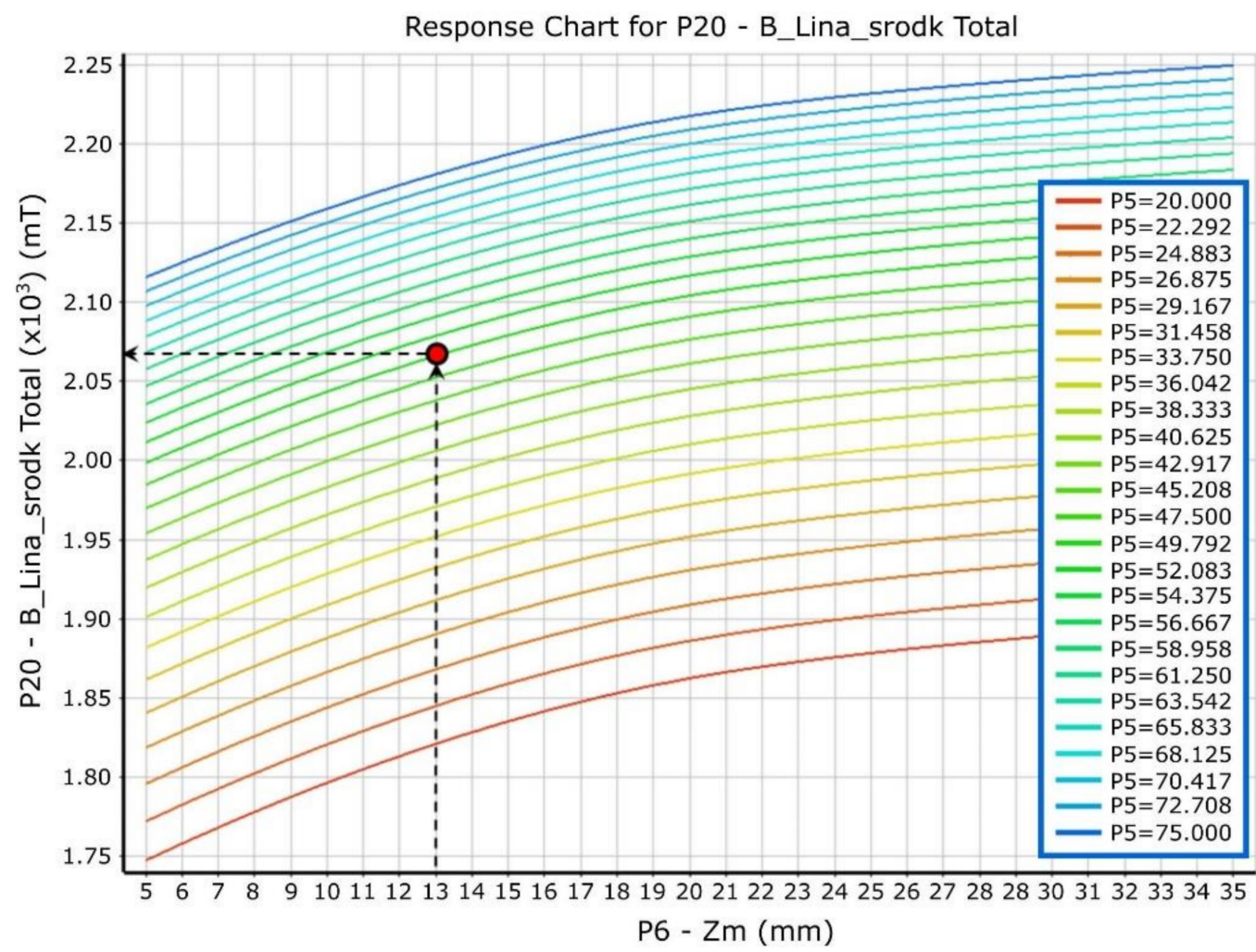

Figure 8. Nomogram (slice plot)—response of output parameter P20 (induction in the central wire rope) as a function of input parameters P6 (magnet height) and P5 (magnet width) (own source).

The adopted target values of the input parameters are presented in Table 3.

Table 3. Selected parameters of the head before and after its modernisation.

\begin{tabular}{|c|c|c|c|c|c|c|c|c|}
\hline \multirow{2}{*}{\multicolumn{2}{|c|}{ Parameter Name }} & \multirow{3}{*}{$\begin{array}{l}\text { Unit } \\
(\mathrm{mm})\end{array}$} & \multicolumn{3}{|c|}{ Before Modernisation } & \multicolumn{3}{|c|}{ After Modernisation } \\
\hline & & & $X$ & $\mathbf{Y}$ & $\mathrm{Z}$ & $X$ & $\mathbf{Y}$ & $\mathrm{Z}$ \\
\hline \multirow{4}{*}{$\begin{array}{l}\text { Dimensions of the } \\
\text { elements of the } \\
\text { magnetic circuit }\end{array}$} & Magnetic jumper & & 195 & 70 & 10 & 185 & 70 & 8 \\
\hline & Pole piece & $(\mathrm{mm})$ & 52 & 70 & 17 & 55 & 70 & 14 \\
\hline & Permanent magnet & $(\mathrm{mm})$ & 50 & 50 & 13 & 50 & 50 & 13 \\
\hline & Complete magnetic circuit & $(\mathrm{mm})$ & 195 & 70 & 40 & 185 & 70 & 35 \\
\hline Weight & Complete magnetic circuit & $(\mathrm{kg})$ & & 2.56 & & & 2.17 & \\
\hline
\end{tabular}

Figure 10 shows the actual results of point measurements of the total magnetic field induction in the defined measurement plane. The analogous data from the numerical analysis of magnetic field distribution is presented in Figure 11.

The similarity of the magnetic field distribution nature as well as the coincidence of magnetic field induction values in the comparable areas of the numerical experiment and real measurements can be clearly seen [31]. 


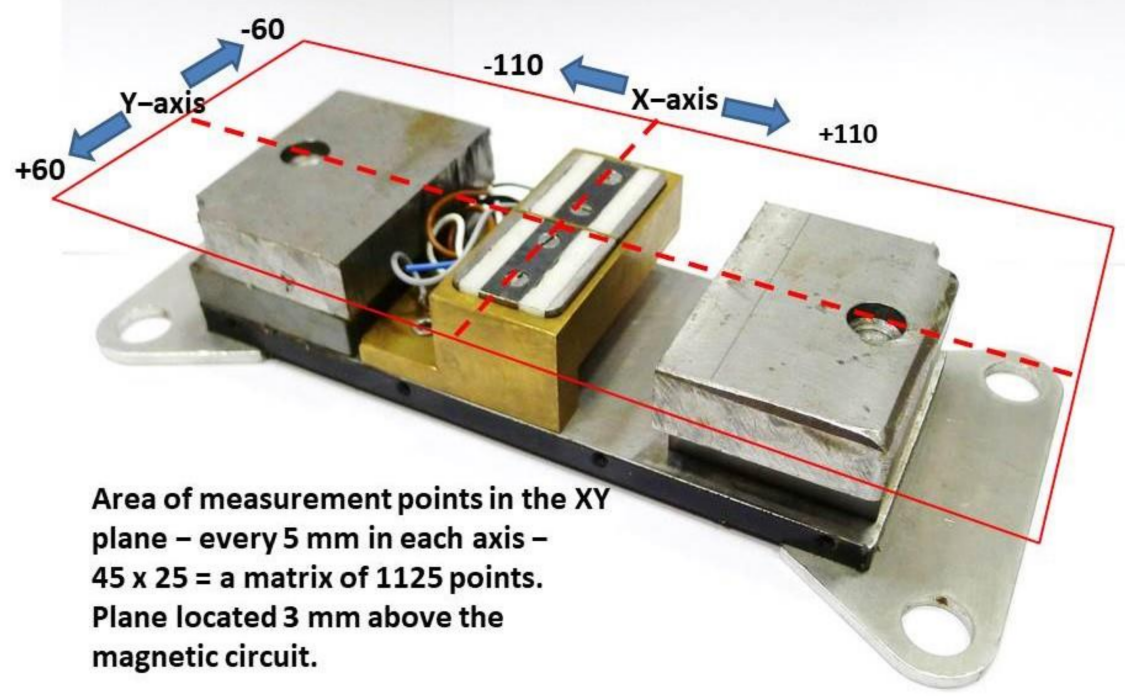

Figure 9. Magnetic circuit of the head after modernisation and measurement plane area (own source).

Total magnetic induction $\mathrm{Bc}(\mathrm{mT}), \mathrm{Z}=3 \mathrm{~mm}$

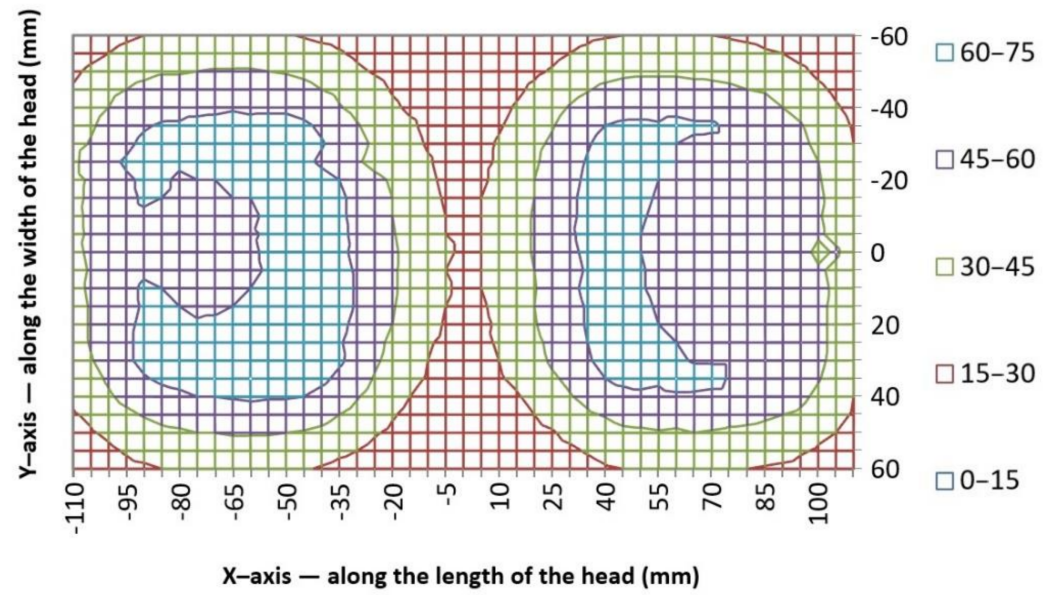

Figure 10. Total magnetic field induction in the defined measurement plane (see Figure 9) (own source).

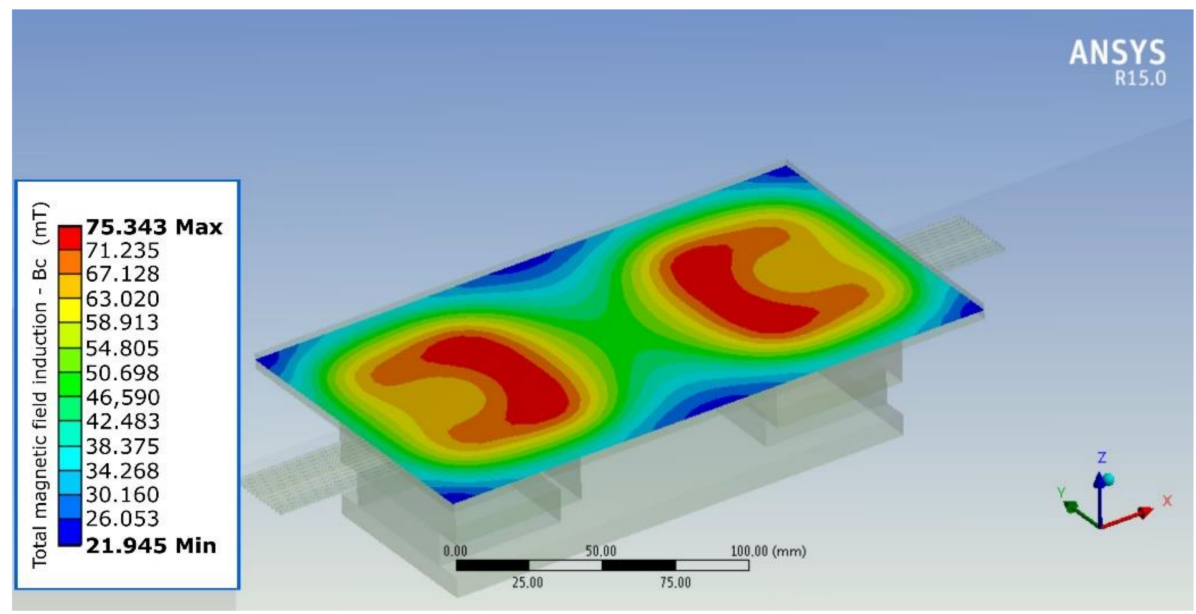

Figure 11. Total magnetic field induction (values form numerical analysis) $-B_{c}$ in the $X Y$ plane $3 \mathrm{~mm}$ above the head (own source). 
Despite the similarity of field distribution and magnetic field induction values in the comparable areas, the \% differences were not referred to quantitatively due to the following facts:

- In real measurements, an inaccuracy of at least $0.5 \mathrm{~mm}$ in the measuring probe location in the ambient space in relation to a point from the numerical analysis may lead to significant discrepancies in the identified value of total induction.

- For numerical analyses, the publicly available magnetic data (primary magnetisation curve $\mathrm{BH}$ ) for the general-purpose ferritic structural steel was used-the actual magnetisation curve of the structural material was not verified in the laboratory. The same procedure was followed for the hard magnetic material (permanent magnet), trusting the magnet parameters declared by the manufacturer. Only the value of the perpendicular component of magnetic field induction to the magnet pole $3 \mathrm{~mm}$ above its surface was verified, obtaining a value of approximately $273 \mathrm{mT}$ from the actual measurement and approximately $270 \mathrm{mT}$ from the numerical simulation of a free magnet in the air space.

- The numerical analysis is an idealised analysis as opposed to a real magnetic circuit. The magnetic circuit elements in the FEM analysis were represented as cuboidal elements with perfectly smooth walls and edges. The actual magnetic circuit was tailored for a useful measuring device and therefore had additional technological holes allowing for the installation of sockets, sensor elements, housings, etc. These small changes and violations of geometry continuity also had little effect on the magnetic field distribution as can be seen in Figure 10, in relation to the ideal and symmetrical magnetic field distribution from the FEM analysis in Figure 11.

- The actual measurement was carried out at points with the resolution of $5 \mathrm{~mm}$ in the $\mathrm{X}$ and $\mathrm{Y}$ axes in the measurement plane, unlike the numerical analysis in which the data were taken continuously from the XY plane.

However, despite the differences shown, the highly convergent results were obtained. This allows us to assume that the numerical results obtained are valid, and the design changes introduced on their basis, affecting the metrological properties, will be successfully validated and confirmed during verification tests.

Apart from optimisation of the magnetic circuit, additional elements made of carbon and stainless steel, which could have caused additional unintentional disturbance of the magnetic field, were eliminated from the existing head. These changes mainly concerned the housing and the guidance system. The FDM 3D printing technology was used for this purpose. The use of this technology made it possible to adjust the guidance system to the dimensions of the tested load-carrying belt more accurately than in the previous solution, which had a positive effect on limiting its vibrations during measurements.

\section{Verification Tests}

The verification tests of two versions of the measuring head were performed using the SP belt built from 10 steel wire ropes of the $7 \times 7$ construction. The metallic cross-section of the belt made of 490 wires was $16.32 \mathrm{~mm}^{2}$; its basic dimensions are shown in Figure 1. The damage in the tested load-carrying belt was modelled by cutting the adjacent outer wires of one of the wire ropes. For this purpose, the outer coating was removed and an appropriate number of wires were cut (Figure 12a). The damage of 3,4, 5, 6, 7, 14, and 21 broken wires in the tested load-carrying belt was modelled, which corresponded to a loss of metallic section of the load-carrying belt in the range of $0.58-4.17 \%$. (Table 4 ). The mutual motion of the measuring head and the load-carrying belt during the test could result in unintentional and unknown changes in the modelled damage, e.g., a change in the air gap size due to the movement of wires or a change in the metallic cross-section loss resulting from the broken wires. From the validation point of view, it was important to keep the damage model unchanged during the whole experiment, therefore the place of its execution was protected with plastic. (Figure 12b). 


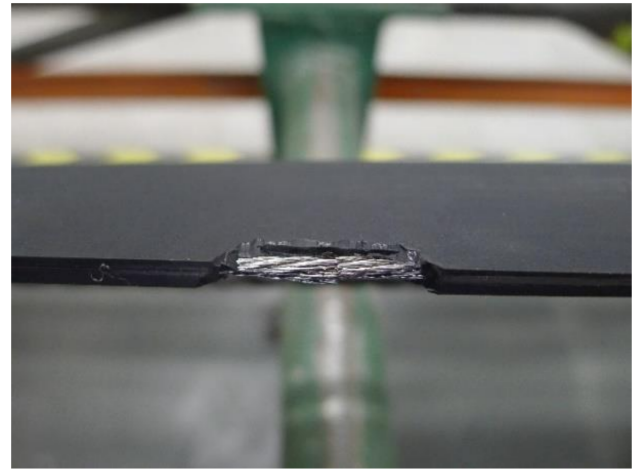

(a)

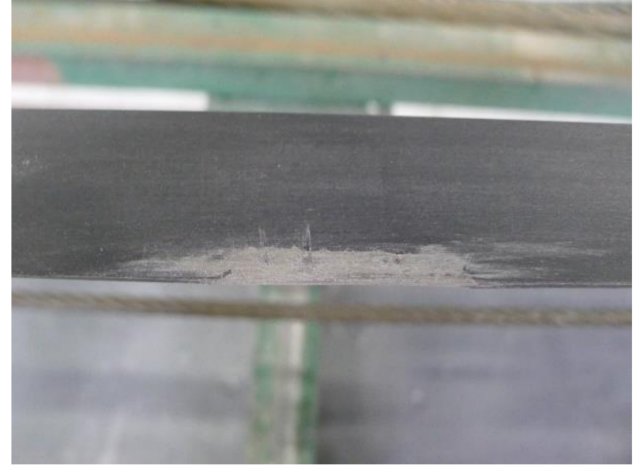

(b)

Figure 12. Modelled defect (a) with removed carcass layer (b) after plastic protection (own source).

Table 4. Size of modelled damage.

\begin{tabular}{ccc}
\hline Number of Broken Wires $\boldsymbol{n}$ & \multicolumn{2}{c}{ Loss of Metallic Cross Section $\boldsymbol{\Delta} \boldsymbol{S}_{\boldsymbol{F e}}$} \\
\hline $\mathbf{( - )}$ & $\mathbf{( \mathbf { m m } ^ { \mathbf { 2 } } )}$ & $\mathbf{( \% )}$ \\
\hline 3 & 0.094 & 0.58 \\
4 & 0.126 & 0.77 \\
5 & 0.157 & 0.96 \\
6 & 0.188 & 1.15 \\
7 & 0.227 & 1.39 \\
14 & 0.453 & 2.78 \\
21 & 0.680 & 4.17 \\
\hline
\end{tabular}

One of the basic requirements of the optimisation carried out was to improve the metrological properties and increase the possibility of detecting the smallest defects, single broken wires, which in the currently used head were often impossible to locate due to the presence of useful signals in the noise envelope. For this reason, the tests were carried out in the damage range from defects in single wires of the smallest diameter. For technical reasons, the smallest possible defect proved to be the incision of 3 wires.

Testing of the load-carrying belt with the use of analysed measuring heads was conducted on a laboratory test bench. The measurement conditions included stable head movement at a constant speed of $0.5 \mathrm{~m} / \mathrm{s}$ along a stationary, pre-tensioned load-carrying belt. The MD121 recorder was used to record the signal, and the same set of belts was used in all cases. For the statistical analysis, the measurement procedure was repeated 10 times under the same conditions. The obtained results of one of the measurements, the recorded voltage signal corresponding to the change of a vertical component of the magnetic stray field over the tested load-carrying belt Us, are presented in Figures 13 and 14.

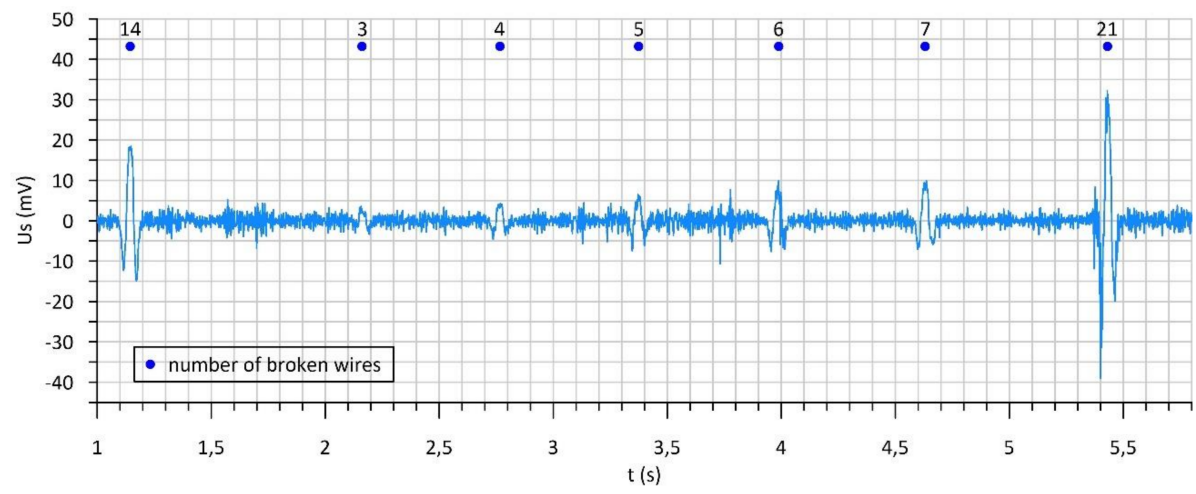

Figure 13. Registered voltage signal corresponding to a change of vertical component of magnetic stray field over the tested load-carrying belt-head before optimisation (own source). 


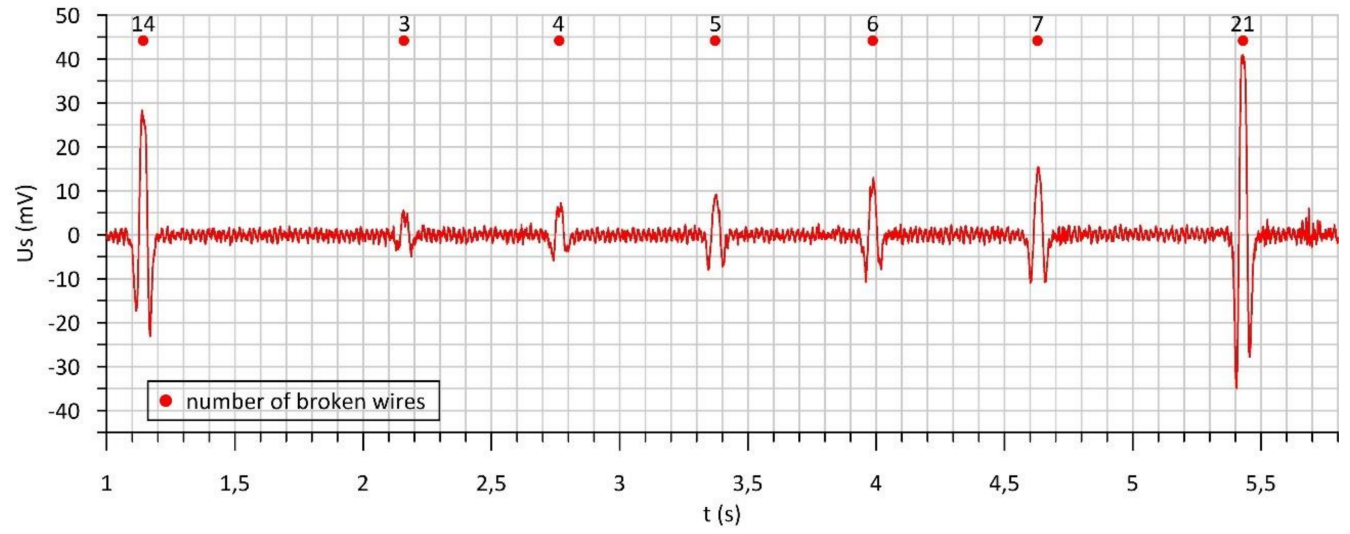

Figure 14. Registered voltage signal corresponding to a change of vertical component of magnetic stray field over the tested load-carrying belt-head after optimisation (own source).

\section{Discussion}

Based on the recorded results for both measuring heads, the dependence of the Us signal as a function of load-carrying belt metal cross-section loss $\Delta \mathrm{S}_{\mathrm{Fe}}$ was plotted (Figure 15a). This relationship for the head after optimisation has a greater angle of inclination against the horizontal axis. The same damages result in diagnostic signals with a higher $\mathrm{A}_{\mathrm{Us}}$ amplitude. The signals recorded with the optimised transducer have a higher signal-to-noise ratio, which is a measure of comparison between the level of useful signal carrying the damage information and the level of background noise. For the optimised system, the maximum noise values do not exceed the amplitude of recorded diagnostic signal originating from the smallest defects. It is possible to unambiguously identify the signal coming from the smallest damage model, i.e., three broken wires.

From the data shown in Figure 15b and Table 5 for the head before optimisation, there are overlaps in the ranges of recorded values for the adjacent quantities. The minimum amplitude values of $A_{U s m i n}$ signals from larger defects overlap with the maximum $A_{U s m a x}$ values of smaller defects. This results in ambiguity in the interpretation of results and may cause a smaller defect to be assigned as a larger defect or conversely a larger defect to be assigned as a smaller defect.

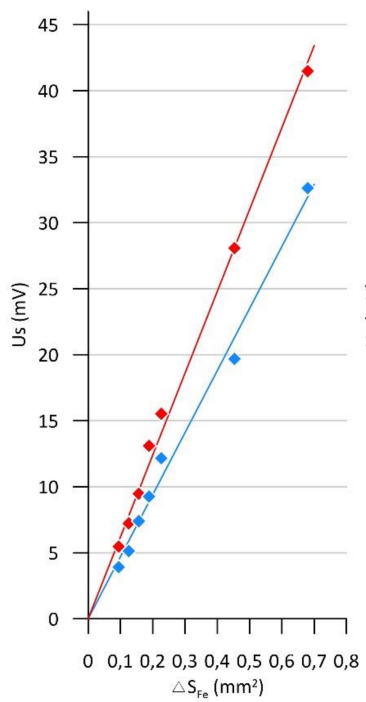

a)

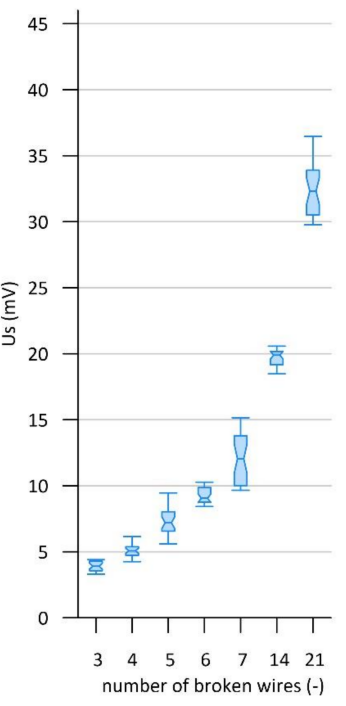

b)

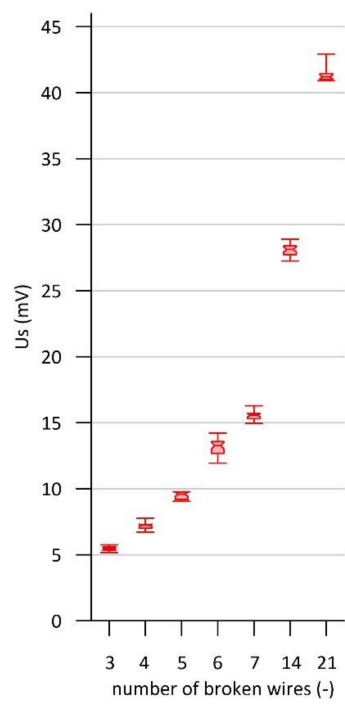

c)

Figure 15. Results of analysis of recorded diagnostic signals (a) dependence of Us signal as a function of load-carrying belt metallic section loss $\Delta \mathrm{S}_{\mathrm{Fe}} ;(\mathbf{b})$ distribution and comparison of statistical features of diagnostic signals recorded with the head before modernisation; (c) distribution and comparison of statistical features of diagnostic signals recorded with the head after modernisation (own source). 
Table 5. Results of statistical analysis of recorded diagnostic signals.

\begin{tabular}{|c|c|c|c|c|c|c|c|c|c|c|c|c|c|c|c|}
\hline \multirow{3}{*}{ Loss of metallic cross section $\Delta \mathrm{S}_{\mathrm{Fe}}$} & $(-)$ & \multicolumn{2}{|c|}{3} & \multicolumn{2}{|c|}{4} & \multicolumn{2}{|c|}{5} & \multicolumn{2}{|c|}{6} & \multicolumn{2}{|c|}{7} & \multicolumn{2}{|c|}{14} & \multicolumn{2}{|c|}{21} \\
\hline & $\left(\mathrm{mm}^{2}\right)$ & \multicolumn{2}{|c|}{0.094} & \multicolumn{2}{|c|}{0.126} & \multicolumn{2}{|c|}{0.157} & \multicolumn{2}{|c|}{0.1880} & \multicolumn{2}{|c|}{0.227} & \multicolumn{2}{|c|}{0.453} & \multicolumn{2}{|c|}{0.680} \\
\hline & $(\%)$ & \multicolumn{2}{|c|}{0.58} & \multicolumn{2}{|c|}{0.77} & \multicolumn{2}{|c|}{0.96} & \multicolumn{2}{|c|}{1.15} & \multicolumn{2}{|c|}{1.39} & \multicolumn{2}{|c|}{2.78} & \multicolumn{2}{|c|}{4.17} \\
\hline Mean signal amplitude $A_{U s}$ & $(\mathrm{mV})$ & 3.91 & 5.48 & 5.14 & 7.22 & 7.40 & 9.47 & 9.27 & 13.11 & 12.16 & 15.54 & 19.67 & 28.09 & 32.62 & 41.47 \\
\hline \multirow{2}{*}{ Standard deviation $\mathrm{s}\left(\mathrm{A}_{\mathrm{Us}}\right)$} & $(\mathrm{mV})$ & 0.35 & 0.17 & 0.56 & 0.31 & 1.21 & 0.27 & 0.62 & 0.65 & 2.02 & 0.34 & 0.63 & 0.48 & 2.28 & 0.67 \\
\hline & $(\%)$ & 9.00 & 3.10 & 10.96 & 4.29 & 16.30 & 2.82 & 6.69 & 4.93 & 16.59 & 2.19 & 3.18 & 1.71 & 2.28 & 1.62 \\
\hline Minimum signal amplitude $A_{\text {Usmin }}$ & $(\mathrm{mV})$ & 3.30 & 5.17 & 4.26 & 6.72 & 5.61 & 9.05 & 8.42 & 11.95 & 9.66 & 14.9 & 18.48 & 27.26 & 29.77 & 40.91 \\
\hline Maximum signal amplitude $A_{U s \max }$ & $(\mathrm{mV})$ & 4.40 & 5.75 & 6.15 & 7.77 & 9.46 & 9.77 & 10.27 & 14.22 & 15.16 & 16.29 & 20.57 & 28.91 & 36.46 & 42.93 \\
\hline First quartile Q1 & $(\mathrm{mV})$ & 3.56 & 5.35 & 4.73 & 7.01 & 6.56 & 9.20 & 8.76 & 12.68 & 10.02 & 15.3 & 19.16 & 27.73 & 30.51 & 41.01 \\
\hline Third quartile Q3 & $(\mathrm{mV})$ & 4.30 & 5.59 & 5.38 & 7.29 & 8.04 & 9.72 & 9.86 & 13.57 & 13.79 & 15.71 & 20.18 & 28.40 & 33.9 & 41.16 \\
\hline \multirow{2}{*}{ Quarterly deviation Q } & $(\mathrm{mV})$ & 0.37 & 0.12 & 0.32 & 0.14 & 0.74 & 0.26 & 0.55 & 0.44 & 1.88 & 0.20 & 0.51 & 0.33 & 1.69 & 0.07 \\
\hline & $(\%)$ & 9.48 & 2.19 & 6.41 & 1.93 & 10.27 & 2.71 & 6.07 & 3.35 & 15.64 & 1.31 & 2.56 & 1.19 & 5.24 & 0.18 \\
\hline
\end{tabular}

Clearly, the optimised head enables to obtain more repeatable results and the standard deviation $\mathrm{s}\left(\mathrm{A}_{\mathrm{Us}}\right)$, which can be equated with measurement uncertainty if any of the measured amplitudes of $\mathrm{A}_{\mathrm{Us}}$ signal were taken as the result, is of a smaller value in its case. For the head before optimisation, the relative standard deviation $\mathrm{s}\left(\mathrm{A}_{\mathrm{Us}}\right)$ is within the range $3.55-30.34 \%$, while after optimisation, it is $3.18-16.59 \%$.

The results of the performed statistical analysis are presented in Table 5. The comparison of statistical features of both diagnostic signals is presented in box plots in Figure 15b,c. The graphs were formed by the distribution parameters such as the first and third quartile, median, minimum, and maximum values. A quartile is in a positional measure group that divides a statistical series describing the structure of a population into four equal parts. The first quartile Q1 (bottom) divides the population into two parts in such a way that $25 \%$ of the population units have the variable values less than or equal to the first quartile Q1, and $75 \%$ equal to or greater than this quartile. The second quartile Q2 divides the population into two parts in such a way that half of the population units have values of the variable equal to or greater than the median, hence it is called the middle value. The third quartile Q3 (top) divides the population into two parts in such a way that $75 \%$ of the community units have variable values less than or equal to the third quartile Q3, and $25 \%$ equal to or greater than this quartile [42,43]. For the values recorded with the optimised head, the first and third quartile values are concentrated closer to the median value. This indicates that the set of values is narrower and less dispersed. The variation degree of the recorded result population set by the quarter deviation $Q$ (Table 5) being half of the difference between the third and the first quartile is within the range of 2.56-15.64\% for the head before modernisation and $0.18-3.35 \%$ for the modernised head. The quarterly deviation measures the level of variation of only a part of the units belonging to the studied population and its value is not affected by the values of units smaller than the first quartile and larger than the third quartile. Therefore, this measure, as opposed to the standard deviation, is not sensitive to extreme (atypical) values [44]. The analysis presented in this paper was developed using one methodology. In order to more effectively optimize the diagnostic system and solve the decision problems, the authors will want to use other, more advanced optimization methods, related to both heuristics and metaheuristics. In particular, future efforts are planned to evaluate the technical condition of load-bearing tendons using an expert system. Solutions of advanced optimization algorithms used in various fields (e.g., planning, transportation, medicine) have been widely described in publications [45-51].

\section{Conclusions}

The results presented in this paper allow to formulate the following final conclusions: 
- The use of simulation methods in various fields of mechanical engineering allows for a significant reduction of the optimisation process time and minimisation of costs associated with intermediate prototypes. Numerical simulations are used not only to optimise the structures in terms of mass or safety-related indices, but also to model, analyse, and optimise the magnetic circuits.

- The optimisation of magnetic circuit made it possible to optimise the magnetic head in terms of metrological properties as well as mass and size criteria. Appropriate selection of the parameters of magnets, air gap, and other circuit elements made it possible to obtain the magnetic field induction in wire ropes of the tested load-carrying belt having the values close to magnetic saturation of their material.

- The correctness of numerical analyses carried out was confirmed by comparing the results obtained with actual measurements of the magnetic field induction in the vicinity of the magnetic circuit.

- The improved functional properties and the reduced weight were also achieved by using $3 \mathrm{D}$ printing technology.

- The optimisation of magnetic circuit and the modernisation of existing measurement head prototype resulted in a better quality of the recorded signal. The signals recorded with the optimised head have a higher signal-to-noise ratio. Thanks to this, it is possible to more easily locate defects with a small loss of metallic cross-section, which until now, due to the value of the signal associated with the defects, was drowned out by the noise component of the signal recorded.

- The comparative measurements carried out in the laboratory were performed under the same measuring conditions and with the same operating parameters. The obtained results allow a more metrologically and ergonomically effective application of the optimised head on real lifting devices.

- In order to confirm the obtained results, further work on the magnetic circuit should be extended to other optimization procedures.

- The obtained results under laboratory conditions should be further confirmed on real devices with different support tendons.

Author Contributions: Conceptualisation, validation, investigation, H.R. and T.K.; writing-original draft preparation, H.R., T.K. and P.L.; writing-review and editing, H.R., T.K. and P.L.; visualisation, H.R., T.K. and P.L. All authors have read and agreed to the published version of the manuscript.

Funding: This research received no external funding.

Institutional Review Board Statement: Not applicable.

Informed Consent Statement: Not applicable.

Data Availability Statement: Data sharing not applicable. The data presented in this study are available on request from the corresponding author.

Conflicts of Interest: The authors declare no conflict of interest.

\section{References}

1. PN-EN. 81-20:2020 Safety Rules for the Construction and Installation of Lifts-Lifts for the Transport of Persons and Goods-Part 20: Passenger and Goods Passenger Lifts; Poland, 2020.

2. GEN2. Technology for Your Existing Building. Available online: https://www.otis.com/documents/256045/6552829/OTISGen2MOD_Final.pdf/b2d0ba43-491b-7ae7-ec73-a710f9d7ba9e?t=1594735223630 (accessed on 9 December 2021).

3. Conti Polyflat. Available online: https://www.continental-industry.com/getmedia/267f7e79-d50f-48a2-9b3b-934b03d7f236 /PTG9267-EnDe_POLYFLAT.pdf (accessed on 9 December 2021).

4. Kwaśniewski, J.; Krakowski, T. Intelligent diagnostic system of flexible polyurethane-coated steel belts. Transp. Logist. 2010, 7, 210-215.

5. Kwaśniewski, J.; Ruta, H. The design of magnetic circuits taking into account measuring application. Electr. Rev. 2011, 87, 60-65.

6. Krakowski, T.; Molski, S.; Ruta, H.; Lonkwic, P.; Tofil, A. Diagnostics of operational wear in hybrid load-carrying cables. J. Phys. Conf. Ser. 2021, 1736, 012012. [CrossRef] 
7. Lonkwic, P.; Krakowski, T.; Ruta, H. Application of stray magnetic field for monitoring the wear degree in steel components of the lift guide rails system. Metals 2020, 10, 1008. [CrossRef]

8. Mańka, E.; Styp-Rekowski, M. Porównanie wybranych wielkości wykorzystywanych do oceny stanu lin określonych różnymi metodami. Stud. Proc. Pol. Assoc. Knowl. Manag. 2011, 47, 157-168.

9. Kwaśniewski, J. Application of the wavelet analysis to inspection of compact ropes using a high-efficiency device. Arch. Min. Sci. 2013, 58, 159-164.

10. Dogonchi, A.S.; Tayebi, T.; Chamkha, A.J. Natural convection analysis in a square enclosure with a wavy circular heater under magnetic field and nanoparticles. J. Therm Anal. Calorim 2020, 139, 661-671. [CrossRef]

11. Sarafraz, M.M.; Pourmehran, O.; Yang, B.; Arjomandi, M.; Ellahi, R. Pool boiling heat transfer characteristics of iron oxide nano-suspension under constant magnetic field. Int. J. Therm. Sci. 2020, 147, 106131. [CrossRef]

12. Malikan, M.; Krasheninnikov, M.; Eremeyev, V.A. Torsional stability capacity of a nano-composite shell based on a nonlocal strain gradient shell model under a three-dimensional magnetic field. Int. J. Eng. Sci. 2020, 148, 103210. [CrossRef]

13. Zarezadeh, E.; Hosseini, V.; Hadi, A. Torsional vibration of functionally graded nano-rod under magnetic field supported by a generalized torsional foundation based on nonlocal elasticity theory. Mech. Based Des. Struct. Mach. 2020, 48, 480-495. [CrossRef]

14. Hosseinzadeh, K.; Roghani, S.; Mogharrebi, A.R. Optimization of hybrid nanoparticles with mixture fluid flow in an octagonal porous medium by effect of radiation and magnetic field. J. Therm Anal. Calorim 2021, 143, 1413-1424. [CrossRef]

15. Qi, C.; Tang, J.; Fan, F.; Yan, Y. Effects of magnetic field on thermo-hydraulic behaviors of magnetic nanofluids in CPU cooling system. Appl. Therm. Eng. 2020, 179, 115717. [CrossRef]

16. Fleishman, G.D.; Gary, D.E.; Chen, B.; Kuroda, N.; Yu, S.; Nita, G.M. Decay of the coronal magnetic field can release sufficient energy to power a solar flare. Science 2020, 367, 278-280. [CrossRef]

17. Izadi, M.; Mikhail, A.S.; Mehryan, S.A.M. Natural convection of a hybrid nanofluid affected by an inclined periodic magnetic field within a porous medium. Chin. J. Phys. 2020, 65, 447-458. [CrossRef]

18. Yongbo, L.; Xiaoqiang, D.; Fangyi W.; Xianzhi W.; Huangchao, Y. Rotating machinery fault diagnosis based on convolutional neural network and infrared thermal imaging. Chin. J. Aeronaut. 2020, 33, 427-438.

19. Tie, S.; Zhao, W.; Xin, D. Robust Fabrication of Hybrid Lead-Free Perovskite Pellets for Stable X-ray Detectors with Low Detection Limit. Adv. Mater. 2020, 32, 2001981. [CrossRef]

20. Suraci, S.V.; Fabiani, D.; Xu, A.; Roland, S.; Colin, X. Ageing Assessment of XLPE LV Cables for Nuclear Applications Through Physico-Chemical and Electrical Measurements. IEEE Access 2020, 8, 27086-27096. [CrossRef]

21. Jin., Y.; Walker, E.; Heo, H. Nondestructive ultrasonic evaluation of fused deposition modeling based additively manufactured 3D-printed structures. Smart Mater. Struct. 2020, 29, 45020. [CrossRef]

22. Gallardo-Saavedra, S.; Hernández-Callejo, L.; Alonso-García, M. Nondestructive characterization of solar PV cells defects by means of electroluminescence, infrared thermography, I-V curves and visual tests: Experimental study and comparison. Energy 2020, 205, 117930. [CrossRef]

23. Weiland, J.; Hesser, D.F.; Xiong, W. Structural health monitoring of an adhesively bonded CFRP aircraft fuselage by ultrasonic Lamb Waves. Proc. Inst. Mech. Eng. Part G J. Aerosp. Eng. 2020, 234, 2000-2010. [CrossRef]

24. Roskosz, M.; Fryczowski, K.; Schabowicz, K. Evaluation of Ferromagnetic Steel Hardness Based on an Analysis of the Barkhausen Noise Number of Events. Materials 2020, 13, 2059. [CrossRef]

25. Roskosz, M.; Fryczowski, K.; Tuz, L.; Wu, J.; Schabowicz, K.; Logoń, D. Analysis of the Possibility of Plastic Deformation Characterisation in X2CrNi18-9 Steel Using Measurements of Electromagnetic Parameters. Materials 2021, 14, 2904. [CrossRef]

26. Molina-Viedma, A.J.; Pieczonka, Ł.; Mendrok, K.; López-Alba, E.; Díaz, F.A. Damage identification in frame structures using high-speed digital image correlation and local modal filtration. Struct. Control. Health Monit. 2020, 27, 1-16. [CrossRef]

27. Kawecki, Z.; Stachurski, J. Defektoskopia Magnetyczna Lin Stalowych, 1st ed.; Wydawnictwo Śląs: Katowice, Poland, 1969; pp. 31-89.

28. Kwaśniewski, J. Badania Magnetyczne Lin Stalowych, System Certyfikacji Personelu w Metodzie MTR, 1st ed.; Wydawnictwa AGH: Kraków, Poland, 2004; pp. 59-99.

29. Tytko, A. Eksploatacja Lin Stalowych, 1st ed.; Wydawnictwo Śląsk: Katowice, Poland, 2003; pp. 301-374.

30. Halliday, D.; Resnick, R.; Walker, J. Basics of Physics 3; Wydawnictwo Naukowe PWN SA: Warszawa, Poland, 2003; pp. 248-251.

31. Ruta, H. Zastosowanie Metod Symulacyjnych w Określaniu Właściwości Metrologicznych Urządzeń Diagnostycznych. Ph.D. Thesis, Kraków, Poland, 2018.

32. Skoczylas, J. Analiza pola magnetycznego magnesu trwałego przy zastosowaniu metody elementów skończonych. Arch. Elektrotechniki 1981, nr 1, 22-30.

33. Kogen-Dalin, W.W.; Komarow, E.W.; Zadrożny, J. Obliczanie i badania układów z magnesami trwałymi; Wydawnictwa NaukowoTechniczne: Warszawa, Poland, 1982.

34. Bolkowski, S.; Stabrowski, M.; Skoczylas, J.; Sroka, J.; Sikora, J.; Wincenciak, S. Komputerowe Metody Analizy Pola Elektromagnetycznego; Wydawnictwa Naukowo-Techniczne: Warszawa, Poland, 1993.

35. Meeker, D. Finite Element Method Magnetics Version 4.2 FEMM Material Database; University of Virginia: Charlottesville, VA, USA, 2015.

36. Moaveni, S. Finite Element Analysis Theory and Application with ANSYS; Pearson Education, Inc: Hoboken, NJ, USA, 2008.

37. Sikora, J. Numeryczne Metody Rozwiazywania Zagadnień Brzegowych-Podstawy Metody Elementów Skończonych i Metody Elementów Brzegowych; Wydawca, Politechnika Lubelska: Lublin, Poland, 2011. 
38. Reh, S.; Beley, J.D.; Mukherjee, S.; Khor, E.H. Probabilistic finite element analysis using ANSYS. Struct. Saf. $2006,28,17-43$. [CrossRef]

39. Serageldin, A.A.; Abdelrahman, A.K.; Ookawara, S. Parametric study and optimization of a solar chimney passive ventilationsystem coupled with an earth-to-air heat exchanger. Sustain. Energy Technol. Assess. 2018, 30, $263-278$.

40. Thacker, V.; Vijayaragavan, E. Design optimization of clutch cushion disc with the integration of finite element analysis and design of experiments. IOP Conf. Ser. Mater. Sci. Eng. 2018, 402, 12053. [CrossRef]

41. Popella, H.; Henneberger, G. Design and optimization of the magnetic circuit of a mobile nuclear magnetic resonance device for magnetic resonance imaging. COMPEL Int. J. Comput. Math. Electr. Electron. Eng. 2001, 20, 269-279. [CrossRef]

42. Malarska, A. Statystyczna Analiza Danych, 1st ed.; SPSS Polska: Kraków, Poland, 2005; pp. 24-39.

43. Potter, K.; Hagen, H.; Kerren, A.; Dannenmann, P. Methods for presenting statistical information: The box plot. Vis. Large Unstr. Data Sets. 2006, 4, 97-106.

44. Jóźwiak, J.; Podgórski, J. Statystyka od Podstaw, 7th ed.; Polskie Wydawnictwo Ekonomiczne: Warszawa, Poland, $2012 ;$ pp. 19-101.

45. Zhao, H.; Zhang, C. An online-learning-based evolutionary many-objective algorithm. Inf. Sci. 2020, 509, 1-21. [CrossRef]

46. Fathollahi-Fard, A.M.; Dulebenets, M.A.; Hajiaghaei-Keshteli, M. Two hybrid meta-heuristic algorithms for a dual-channel closed-loop supply chain network design problem in the tire industry under uncertainty. Adv. Eng. Inform. 2021, 50, 101418. [CrossRef]

47. Dulebenets, M.A. A Delayed Start Parallel Evolutionary Algorithm for just-in-time truck scheduling at a cross-docking facility. Int. J. Prod. Econ. 2019, 212, 236-258. [CrossRef]

48. Liu, Z.; Wang, Y.; Huang, P. A many-objective evolutionary algorithm with angle-based selection and shift-based density estimation. Inf. Sci. 2020, 509, 400-419. [CrossRef]

49. Pasha, J.; Dulebenets, M.A.; Kavoosi, M. An Optimization Model and Solution Algorithms for the Vehicle Routing Problem with a "Factory-in-a-Box". IEEE Access 2020, 8, 134743-134763. [CrossRef]

50. Dulebenets, M.A.; Pasha, J.; Abioye, O.F. Exact and heuristic solution algorithms for efficient emergency evacuation in areas with vulnerable populations. Int. J. Disaster Risk Reduct. 2019, 39, 101114. [CrossRef]

51. D'Angelo, G.; Pilla, R.; Tascini, C. A proposal for distinguishing between bacterial and viral meningitis using genetic programming and decision trees. Soft Comput. 2019, 23, 11775-11791. [CrossRef] 